\title{
Bacterial Isolates of Early Onset Neonatal Sepsis and Their Antibiotic Susceptibility Pattern
}

\author{
Md. Abdul Mannan ${ }^{1 *}$ \\ Shahed lqbal ${ }^{2}$ \\ S M Rezaul Karim ${ }^{3}$ \\ Talim Uddin Ahmed $^{4}$ \\ Md. Hakimul Haque Khan ${ }^{4}$ \\ Ashraf Uddin Ahmed ${ }^{4}$ \\ Subir Dey ${ }^{1}$ \\ Sabina Yasmin ${ }^{1}$ \\ Navila Ferdous ${ }^{1}$
}

'Department of Neonatology Ad-din Medical College Hospital Dhaka, Bangladesh.

${ }^{2}$ Department of Pediatrics

Chattagram Maa Shishu-O-General Hospital Chittagong, Bangladesh.

${ }^{3}$ Department of Pediatric Surgery Ad-din Medical College Hospital Dhaka, Bangladesh.

${ }^{4}$ Department of Pediatrics Ad-din Medical College Hospital Dhaka, Bangladesh.

\section{*Correspondence to:}

\section{Dr. Md. Abdul Mannan}

Professor of Neonatology

Department of Neonatology

Ad-din Medical College Hospital

Dhaka-1217, Bangladesh.

Mobile : +88 01957322784

Email :dr_amannan@yahoo.com

www.banglajol.info/index.php/CMOSHMCJ

\begin{abstract}
Background: Neonatal infections are the commonest cause of neonatal mortality along with perinatal asphyxia and consequence of Prematurity and Low Birth Weight (LBW) in Bangladesh. Early Onset Neonatal Sepsis (EONS) is neonatal sepsis occurring within the first 72 hours of birth and it is much more fulminant and has a higher mortality than Late Onset Sepsis (LOS). Sepsis in neonate remains a significant cause of mortality and morbidity in developing countries. Changing bacterial flora and emergence of resistant strains adds to the problem. Thus, neonatal sepsis requires accurate and timely clinical and laboratory diagnosis and proper management for better outcome. The organisms responsible for Early Onset Sepsis (EOS) are different than Late Onset Sepsis (LOS). In this study an attempt has been made to know the positivity rate of EOS and profile of bacteria responsible for EOS and determine the antimicrobial sensitivity pattern that were investigated for rule out sepsis. Methods: This was a prospective observation single centre study over a period of nine months (January to September, 2017) conducted on neonates born at Ad-din Medical College Hospital (AMCH), Dhaka and subsequently admitted in Neonatal Intensive Care Unit (NICU) within 72 hours of birth that were investigated for rule out sepsis. Dual blood sample for cultures from separate area along with essential investigations were sent by collecting samples under aseptic precautions. Empirical antimicrobial therapy was started according to antimicrobial guidelines in the NICU. The blood cultures test were carried out by BD BACTEC automated blood culture system and susceptibility testing was done for all blood culture isolates according to the criteria of the National Committee for Clinical Laboratory Standards by disk diffusion method. Results: A total of 700 neonates were investigated to rule out sepsis and $5.43 \%$ neonates were found with culture proven sepsis in the study. The gram positive bacteria accounted for $71 \%$ and gram negative $29 \%$ of the total isolates. Out of total 38 isolates, Coagulase-Negative Staphylococci (CONS) (68.4\%) was the commonest followed by Acinetobacter (18.4\%) and E. coli (7.9\%) was common culture isolates. Among the gram positive, CONS (96.3\%) was commonest isolate and in gram negative Acinetobacter (63.6\%) was the most prevalent bacteria followed by E.coli (27.3\%). Gram positive isolate, especially CONS (68.4\%) was the major culprit for the early onset sepsis. Among the commonly used antibiotics, the susceptibilities were remarkably low to Amikacin (16\%) in comparison to Ampicillin (42\%) Cefotaxime (45\%) and moderately high to Gentamicin (58\%) for both gram positive \& gram negative isolates. All (100\%) gram positive isolates were resistant to Amikacin. Majority of the gram positive showed low susceptibilities to Meropenem (22\%) Ciprofloxacin (41\%) Ampicillin (48\%) \& Oxacillin (48\%) in comparison to Cefotaxime (52\%) Levofloxacin (55\%) Gentamicin (70\%), Linezolid (70\%) and Vancomycin $(74 \%) .50 \%$ of Coagulase Negative Staphylococcus (CONS) were resistant to Methicillin/Oxacillin. The sensitivity pattern of majority of gram negative isolates
\end{abstract}


showed high level of resistance to Piperacillin+Tazobacterm (9\%) and Ampicillin (27\%) Gentamicin (27\%) Cefotaxime $(27 \%)$ less sensitive to Ciprofloxacin (45\%); moderately high to Levofloxacin (54\%) \& Amikacin (54\%) and highly sensitive to Imipenem/Meropenem (73\%) \& Colistin (91\%). Gentamicin (58\%) and Levofloxacin (55\%) were showed marginal superiority compared to Ampicillin (42\%) and Cefotaxime (45\%) for effective coverage of both. Conclusion: Present study indicated that gram positive species especially CONS continue to be the predominant causative organism followed by Acinetobacter and E. coli in gram negative species. The antibiotic susceptibility profile suggested that for a given cohort empiric (initial) choice of Ampicillin and Gentamicin in EOS. Routine bacterial surveillance and their sensitivity patterns must be an essential component of neonatal care.

Key words: Early Onset Neonatal Sepsis (EONS); Culture isolates; Antimicrobial sensitivity.

\section{INTRODUCTION}

Neonatal infections are the commonest cause of neonatal mortality along with perinatal asphyxia and consequence of Prematurity \& LBW in Bangladesh ${ }^{1}$. Mortality related to neonatal sepsis is more common in developing countries compared with developed countries ${ }^{2}$. The first 28 days of life the neonatal period are the most vulnerable time for a child's survival. Children face the highest risk of dying in their first month of life, at a global rate of 19 deaths per 1,000 live births ${ }^{3}$. Neonatal deaths account for $46 \%$ of all deaths among children under 5 . Globally 2.6 million children died in the first month of life approximately 7,000 newborn deaths every day. The majority (75\%) occurs during the first week of life, and about 1 million newborns die within the first 24 hours. The main causes of newborn deaths are preterm birth related complications (35\%) intrapartum related events (24\%) and serious infections (21\% sepsis or meningitis and pneumonia). These causes account for nearly $80 \%$ of deaths in this age group and almost all of these deaths occur in developing countries ${ }^{3}$. In Bangladesh neonatal death is still high, accounting for more than half of all under-five deaths and more than two-thirds of infant deaths. An estimated 62,000 newborns die every year in Bangladesh and $50 \%$ of them die on 1 st day of life ${ }^{3}$. The main causes of neonatal deaths are prematurity (29.7 percent), birth asphyxia and trauma ( 22.9 percent) $\&$ sepsis (19.9 percent) and account for around $75 \%$ on total death $^{4,1}$. Neonatal sepsis remains as an important cause of morbidity and mortality among infants in developing countries accounting for $30-50 \%$ of total deaths per year ${ }^{5}$. The incidence of neonatal sepsis depends on geographic area and may vary from country to country as well as within the same country. In developing countries, neonatal mortality resulting from all causes of neonatal sepsis is about 34 per 1000 live birth, occurring mainly in the first week of life' whilst it is 5 per 1000 live birth in developed country ${ }^{6}$. Global Infant Mortality Rate (IMR) is $31 / 1000$ live birth and in Bangladesh it is 28/1000 live birth.
Out of them about $70 \%$ of death occur neonatal period and Neonatal Mortality Rate (NMR) in our country 20/1000 live birth and it is marginally higher in comparison of global rate, $19 / 1000$ livebirth $^{7}$. Neonatal sepsis has been classified as either early onset (The first 72 hours of life) or late onset sepsis (Occurring after 3 days of age) i.e. infections occurring before and after 72 hours of life ${ }^{8}$. The reported incidence of neonatal sepsis varies from 7 to 38 per 1000 live birth in Asia, from 6.5 to 23 per 1000 live birth in Africa and from 3.5 to 8.9 per 1000 live birth in South America and the Caribbean ${ }^{9-12}$. By comparison, rates reported in the United States and Australia range from 6-9 per 1000 live birth and in Europe 0.3-3\% per 1000 live birth $^{13-15}$. Early onset bacterial infection places the neonate at risk of death and long term morbidity ${ }^{16,17.18}$. Improvement in outcome and successful treatment depends on early initiation of appropriate antibiotic therapy. The pattern of causative organisms has been constantly changing and the frequent emergence of resistant bacteria compounds the problem further ${ }^{19,13}$. This highlights the need for surveillance of sepsis for optimum therapy. Knowledge of likely causative organisms and their antimicrobial sensitivity pattern could aid in choosing prompt and appropriate therapy for Early Onset Neonatal Sepsis (EONS). The epidemiology of EONS in the developed and developing countries shows some important differences in the pattern of etiological bacteria and their antibiotic susceptibility ${ }^{16,17,18,20,21}$. In developed countries, Group B Streptococcus (GBS) was the common etiological agent for EONS ${ }^{20,21}$. Following adoption of preventive strategies for GBS, Escherichia coli (E.coli) was identified as predominant pathogen ${ }^{21,22}$. Developing nations reported an entirely a different bacterial spectrum ${ }^{18,21,23,24,25}$. In most developing countries, gram negative bacteria remain the major cause of neonatal sepsis (EONS) ${ }^{26,27}$. These organisms developed increased drug resistance over the last two decades ${ }^{28}$. Since the spectrum of organisms that cause neonatal sepsis changes over time and varies from region to region and hospital to hospital even in the same city or the country, it is necessary to have periodic surveillance to understand the changing pattern of organism causing neonatal sepsis. In addition rapidly changing antibiotic sensitivity pattern of bacterial agent causing neonatal sepsis, making its management more difficult for the health care providers ${ }^{29}$. Therefore knowledge of the pattern of bacterial isolates and their antimicrobial susceptibility is useful for treating patients with appropriate empiric antibiotics. Although an extensive research is available worldwide but a few reports are available on neonatal sepsis in Bangladesh ${ }^{28,30}$.

\section{MATERIALS AND METHODS}

The present study was undertaken to find out the positivity rate of EONS and identify the bacterial isolates responsible for EOS and their antibiotic sensitivity pattern that were investigated for rule out sepsis, admitted in tertiary care NICU at Ad-din Medical College Hospital, Dhaka, from January to September 2017. 
This was a prospective observation single centre study conducted on neonates born at AMCH, Dhaka and admitted in the Neonatal Intensive Care Unit (NICU) over a period of 9 months from January to September 2017. All neonates were investigated for rule out sepsis admitted here within 72 hours of birth with a fulfilling the following admission criteria:

i) Gestational age less than 34 weeks (GA $<34 \mathrm{wks}$ )

ii) Birth weight less than $1.8 \mathrm{~kg}(\mathrm{BW}<1800 \mathrm{gm})$

iii) Unwell/sick Neonates e.g. respiratory distress, suspected sepsis, requires oxygen supplementation, convulsion, etc

iv) After prolonged resuscitation

v) Neonates need mechanical ventilation

vi) Severe congenital anomalies

vii) Any Neonates requiring surgery

viii) Neonates with cord $\mathrm{pH}$ less than 7.0 and metabolic acidosis in early neonatal arterial blood sample $(\mathrm{pH}<7.20$ and base deficit $\geq 12 \mathrm{mmol} / \mathrm{L}$ ) within first hour of birth irrespective of gestation

ix) Hypoglycemia (If persistent despite oral feeds or if $<1.1 \mathrm{mmol} / \mathrm{L})$.

Exclusion criteria included:

i) Postnatal age more than 72 hours, and

ii) The outborn neonates.

Written informed consent was obtained from their parents and was investigated for bacterial etiologic agents. Clinical and other relevant data were obtained by attending pediatrician and were transferred to the questionnaire prepared for this study. Studied neonates were limited to timing as early onset (From birth to 72 hours old) sepsis. Dual blood culture, chest X-ray and laboratory tests including Complete Blood Count (CBC) C- Reactive Protein (CRP) Blood Sugar (BS) and serum electrolytes were performed for all subjects. Dual sample for blood culture was sent from separate area. An area of approximately 5 $\mathrm{cm}$ over the venipuncture site was disinfected with $70 \%$ alcohol, rubbing vigorously and allowed to dry. This was followed by application of povidine Iodine in concentric circles over the site and allowed to dry for at least 1 minute. About 1-2 ml venous blood was drawn from the peripheral vein for each culture and then the blood was inoculated into a BD BACTEC Peds plus culture vials $(40 \mathrm{ml})$. The specimens were transported immediately to microbiological laboratory and the test were carried out by BD BACTEC automated blood culture system \& incubated for 120 hours in $37^{\circ} \mathrm{C}$ and were daily checked for evidence of bacterial growth. For positive cultures, subcultures were made solid media (Blood agar and McConkey agar) and were incubated in $37^{\circ} \mathrm{C}$ for 24 to 48 hours. The grown bacteria were identified by colony morphology, gram stain and biochemical tests. Diagnostic microbiology cultures which did not yield any growth following subcultures were reported negative at the end of 5 days. Antimicrobial susceptibility testing was done for all blood culture isolates according to the criteria of the National Committee for Clinical Laboratory Standards by disk diffusion method. Those positive reports had suspicion of contamination were discarded.

\section{RESULTS}

Total 700 neonates were investigated for rule out sepsis \& 38 neonates were found positive blood cultures and the positivity rate was $5.43 \%$. Out of 38 isolates of EONS, gram positive were contributed $71 \%(n=27)$ \& gram negative $29 \%(n=11)$. CONS (68.4\%) was the commonest followed by Acinetobacter (18.4\%) \& E.coli (7.9\%) were common culture isolates. Gram positive especially CONS $(68.42 \%)$ were major culprit for EONS (Table 1).

Among the gram positive, CONS $96.3 \%(n=26)$ was the commonest isolate, other gram positive was streptococcus viridans $3.7 \%(n=1)$. And in gram negative, Acinetobacter $63.6 \%(n=7)$ was the most prevalent bacteria followed by E.coli $27.3 \%$ $(\mathrm{n}=3)$, other was Enterobacter $9.1 \%(\mathrm{n}=1)$.

Based on the results from susceptibility testing gram positive organism had highly sensitivity to Vancomycin $74 \%(\mathrm{n}=20)$ Gentamicin 70\% $(n=19)$ \& Linezolid 70\% ( $n=19)$. Moderate sensitivity to Levofloxacin $55 \%(\mathrm{n}=15)$ Cefotaxime $52 \%$ $(n=14)$ Ampicilin $48 \%(n=13)$ \& Oxacillin 48\% ( $n=13)$. Less sensitive to Ciprofloxacin $41 \%(n=11)$. And remarkably lower sensitivity to Meropenem $22 \%(n=6)$ and $100 \%$ (all) resistant to Amikacin. Among the staphylococci (CONS) 50\% (n=13) were resistant to Methicillin/Oxacillin and 100\% resistant to Amikacin. Meropenem 23\% ( $\mathrm{n}=6)$ and Ciprofloxacin 38\% (n=10) showed remarkably lower sensitivity in comparison to Gentamicin 73\% $(n=19)$ Vancomycin $73 \%(n=19)$ Linezolid $69 \%(n=18)$ and Levofloxacin 54\% $(\mathrm{n}=14) .50 \%(\mathrm{n}=13)$ of CONS were sensitive to Ampicillin, Cefotaxime and Oxacillin (Table 2).

All gram negatives were highly sensitive to Colistin $91 \%$ $(n=10)$ \& Meropenem/Imipenem 73\% $(n=8)$. Moderate sensitive to Amikacin 54\% $(n=6)$ and Levofloxacin 54\% $(n=6)$. Less sensitive to Ciprofloxacin $45 \%(\mathrm{n}=5)$ and remarkably lower sensitivity to Ampicillin (27\%) Gentamicin (27\%) and Cefotaxime $(27 \%)(n=3)$. And near resistant to Piperacillin+Tazobacterm $9 \%(n=1)$. Most common gram negative organism was Acinetobacter $63.6 \%(\mathrm{n}=7)$ which was highly sensitive to Colistin $86 \%(n=6)$ and moderate sensitive to Imipenem/Meropenem $57 \%(n=4)$. Less sensitive to Amikacin 29\% (n=2) and Ciprofloxacin/Levofloxacin 29\% (n=2) and 100\% (all) resistant to Ampicillin, Gentamicin, Cefotaxime and Piperacillin+Tazobacterm. Second common gram negative organism was E. coli $27.3 \%(n=3)$, all (100\%) were sensitive to Ampicillin, Gentamicin, Amikacin, Cefotaxime, Ciprofloxacin/ levofloxacin, Meropenem/Imipenem and Colistin. And 100\% resistant to Piperacillin+Tazobacterm (Table 3).

Table 1 : Profile of isolates in neonates with EONS Type of bacterial isolates Total no. of isolates Percentage (\%)

\begin{tabular}{lcc} 
Gram positive isolates & 27 & $71 \%$ \\
CONS & 26 & $68.4 \%$ \\
Streptococcus viridans & 01 & $2.6 \%$ \\
Gram negative isolates & 11 & $29 \%$ \\
Acinetobacter & 07 & $18.4 \%$ \\
E.coli & 03 & $7.9 \%$ \\
Enterobacter & 01 & $2.6 \%$ \\
Total & 38 & $100 \%$ \\
\hline
\end{tabular}




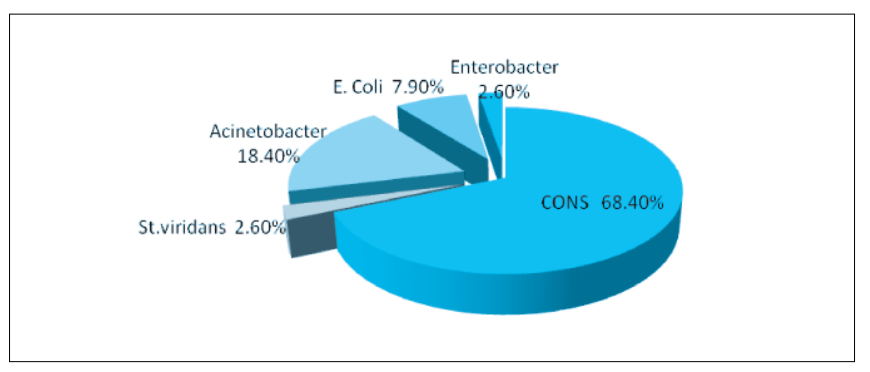

Figure 1: Profile of isolates

Table 2 : Antimicrobial sensitivity of gram positive isolate

$\begin{array}{lllllllllll}\begin{array}{l}\text { Gm +ve } \\ \text { organism no (\%) }\end{array} & \text { Amp } & \text { GM } & \text { Mp } & \text { Lz } & \text { Vn } & \text { 0xa } & \text { Cp } & \text { Lev } & \text { cft } & \text { Amk } \\ \text { CONS (26) } & 13 & 19 & 6 & 18 & 19 & 13 & 10 & 14 & 13 & 0 \\ 96.3 \% & (50 \%) & (73 \%) & (23 \%) & (69 \%) & (73 \%) & (50 \%) & (38 \%) & (54 \%) & (50 \%) \\ \text { Strepto-coccus } & 0 & 0 & 0 & 1 & 1 & 0 & 1 & 1 & 1 & 0 \\ \text { viridans } & & & & (100 \%) & (100 \%) & & (100 \%) & (100 \%) & (100 \%) \\ (1), 37 \% & & & & & & & & & & \\ \text { Total (27) } & 13 & 19 & 6 & 19 & 20 & 13 & 11 & 15 & 14 & 0 \\ 100 \% & (48 \%) & (70 \%) & (22 \%) & (70 \%) & (74 \%) & (48 \%) & (41 \%) & (55 \%) & (52 \%)\end{array}$

CONS: Coagulase Negative Staphylococcus, Amp: Ampicillin, GM: Gentamicin, Amk: Amikacin, Mp: Meropenem, Lz: Linezolid, Vn: Vancomycin, , Oxa: Oxacillin, Cp: Ciprofloxacin, Lev: Levofloxacin ,Cft: Cefotaxime.

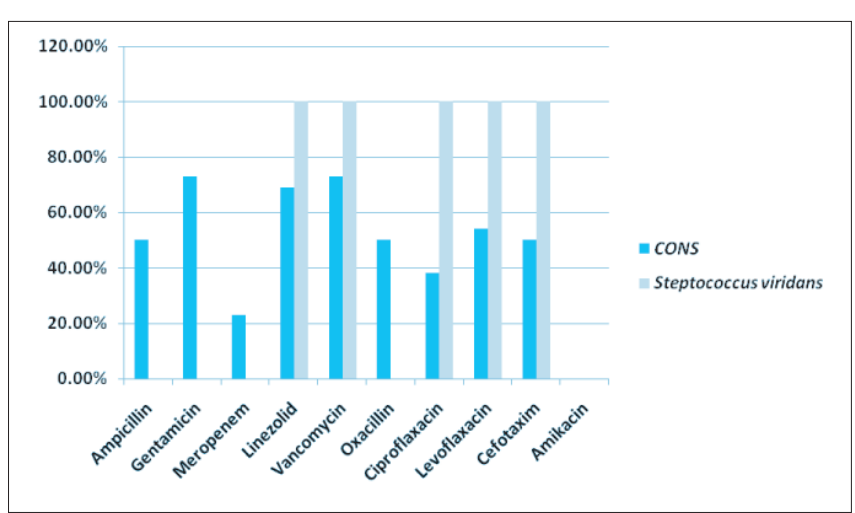

Figure 2 : Antimicrobial sensitivity of gram positive isolate

Table 3 : Antimicrobial sensitivity of gram negative organism

\begin{tabular}{|c|c|c|c|c|c|c|c|c|c|}
\hline $\begin{array}{l}\text { Gm-ve organ } \\
\text { No }(\%)\end{array}$ & Amp & GM & Amk & $\mathrm{Cp}$ & Imip/M & $n \mathrm{I}$ & Pip & $\mathrm{Col}$ & eft \\
\hline $\begin{array}{l}\text { Acinetobacter } \\
\text { (7), } 63.6 \%\end{array}$ & & 0 & $\begin{array}{l}2 \\
(29 \%)\end{array}$ & $\begin{array}{l}2 \\
(29 \%)\end{array}$ & $\begin{array}{l}4 \\
(57 \%)\end{array}$ & $\begin{array}{l}2 \\
(29 \%)\end{array}$ & 0 & $\begin{array}{l}6 \\
(86 \%)\end{array}$ & 0 \\
\hline $\begin{array}{l}\text { E. Coli } \\
(3), 27.3 \%\end{array}$ & $\begin{array}{l}3 \\
(100 \%)\end{array}$ & $\begin{array}{l}3 \\
(100 \%)\end{array}$ & $\begin{array}{l}3 \\
(100 \%)\end{array}$ & $\begin{array}{l}3 \\
(100 \%)\end{array}$ & $\begin{array}{l}3 \\
(100 \%)\end{array}$ & $\begin{array}{l}3 \\
(100 \%)\end{array}$ & 0 & $\begin{array}{l}3 \\
(100 \%)\end{array}$ & $\begin{array}{l}3 \\
(100 \%)\end{array}$ \\
\hline $\begin{array}{l}\text { Enterobacter } \\
(1),(9.1 \%)\end{array}$ & 0 & 0 & $\begin{array}{l}1 \\
(100 \%)\end{array}$ & 0 & $\begin{array}{l}1 \\
(100 \%)\end{array}$ & $\begin{array}{l}1 \\
(100 \%)\end{array}$ & $\begin{array}{l}1 \\
(100 \%)\end{array}$ & $\begin{array}{l}1 \\
(100 \%)\end{array}$ & 0 \\
\hline $\begin{array}{l}\text { Total } \\
\text { (11), 100\% }\end{array}$ & $\begin{array}{l}3 \\
(27 \%)\end{array}$ & $\begin{array}{l}3 \\
(27 \%)\end{array}$ & $\begin{array}{l}6 \\
(54 \%)\end{array}$ & $\begin{array}{l}5 \\
(45 \%)\end{array}$ & $\begin{array}{l}8 \\
(73 \%)\end{array}$ & $\begin{array}{l}6 \\
(54 \%)\end{array}$ & $\begin{array}{l}1 \\
(9 \%)\end{array}$ & $\begin{array}{l}10 \\
(91 \%)\end{array}$ & $\begin{array}{l}3 \\
(27 \%)\end{array}$ \\
\hline
\end{tabular}

Escherichia coli (E.coli), Amp: Ampicillin, GM: Gentamicin, Amk: Amikacin, Imip:Imipenem, Mp: Meropenem, Cp: Ciprofloxacin, Lev: Levofloxacin, PIP: Piperacillin, Col: Colistin, Cft: Cefotaxime.

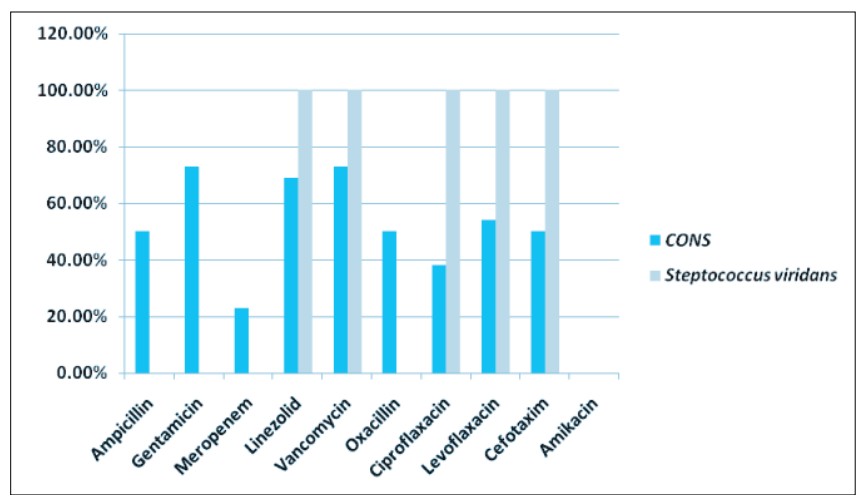

Figure 3: Antimicrobial sensitivity of gram negative organism

\section{DISCUSSIONS}

Sepsis is an important cause of neonatal morbidity and mortality. The incidence and the causative organisms of sepsis vary from place to place. In this study, prevalence of documented early onset neonatal sepsis with positive culture was $5.43 \%$ .This is low compared to about $20 \%$ yield reported by Baltimore et al and Gladstone et al and $26 \%$ by Ahmed et al but near $(8.7 \%)$ to Jahan $\mathrm{N}$ et al study ${ }^{22,31,25,32}$. Isolation of gram positive and gram negative bacteria in this study was $71 \%$ and $29 \%$ respectively. This study finding is opposite to that of other studies which shows that gram negative bacteria were the commonest cause of early onset neonatal sepsis $2,25,32,33$. This was similar to other studies which shows gram positive bacteria are the common cause of neonatal sepsis while Umran $\mathrm{K}$ studies showed, the frequency of isolation of gram positive and gram negative bacteria were equal ${ }^{12,26,34,35}$. Coagulase Negative Staphylococcus (CONS) was the most common isolates (68.4\%) causing EONS followed by Acinetobacter (18.4\%) and E. coli $(7.9 \%)$ isolated in the study. This study is similar to the study which shows gram positive bacteria such as, CONS, Staphylococcus Aureus and Group B Streptococcus (GBS) were found to be the most common causes of neonatal sepsis, Robillard PY, Mugalu J and Ramesh Bhat ${ }^{12,34,36}$. But this study result is opposite to studies of most developing countries where showed gram negative organisms were the common cause of EONS $^{32,37,38}$. In the present study, CONS showed 50\% resistant to Methicillin/Oxacillin and $100 \%$ resistant to Amikacin. Meropenem (23\%) and Ciprofloxacin (38\%) showed remarkably lower sensitivity in comparison to Gentamicin (73\%) Vancomycin (73\%) Linezolid (69\%) and Levofloxacin (54\%). 50\% of CONS were sensitive to Ampicillin, Cefotaxime and Oxacillin. These findings similar to study Haque $\mathrm{ZSM}^{38}$. All gm negative bacteria were highly sensitive to Colistin (91\%) and Meropenem/Imipenem (73\%) moderate sensitive to Amikacin (54\%) and Levofloxacin (54\%) less sensitive to Ciprofloxacin (45\%) and Ampicillin/ Gentamicin/Cefotaxime (27\%) and high level of resistance to Piperacillin+Tazobacterm (9\%). Higher susceptibility to Meropenem/Imipenem (74\%) and Colistin (97\%) was reported by Haque $\mathrm{ZSM}^{38}$. Low sensitivity to Ampicillin, 
Gentamicin and Cefotaxime is similar to many earlier studies. ${ }^{13,38,39,40}$. High level of resistance to Piperacillin+ Tazobacterm is opposite to study of Haque ZSM where found $78 \%$ sensitivity ${ }^{38}$.

Among the commonly used antibiotics, the susceptibilities to Ampicillin (42\%) Cefotaxime (45\%) and moderately high to Gentamicin (58\%) for both gram positive \& gram negative species. Amikacin (16\%) showed remarkably lower sensitivity, so it cannot be used in initial combination. As Ampicilin and Gentamicin had a moderate to high sensitivity, so that can be used as initial antibiotic combination as empiric therapy before preliminary blood culture reports are available. However these results are limited to study cohorts and every center should have idea about their own bacterial sensitivity pattern. Different Neonatal Intensive Care Unit (NICU) shows different epidemiological data for neonatal sepsis. So collection of up-to-date \& site specific data is mandatory for appropriate use of antibiotics.

\section{CONCLUSION AND RECOMMENDATION}

Present study indicated that gram positive species especially CONS continue to be the predominant causative organism in EONS followed by Acinetobacter and E. coli in gram negative species. The antibiotic susceptibility profile suggested that for a given cohort empiric (initial) choice of Ampicillin and Gentamicin in EONS is the most rational.

\section{DISCLOSURE}

All the authors declared no competing interest.

\section{REFERENCES}

1. Bangladesh Demographic and Health Survey (BDHS). 2004;127-130.

2. Moniri R, Movahendian AH, Mosayebi Z. Bacterial Culture of Neonatal Sepsis .Iranian J Publ Health. 2006; 35:84-89.

3. UNICEF: Levels and Trends in Child Mortality Report.2017; 1-25.

4. UNICEF: Maternal and Newborn Health Disparities in Bangladesh.2015; 3-4.

5. Bang AT, Reddy HM, Deshmukh MD, Baitule SB, Bang RA. Neonatal and infant mortality in the ten years (1993 to 2003) of the Gadchiroli field trial: effect of home based neonatal care. J Perinatol. 2005; 25 : S 92-107.

6. Francis V, Costello A, Byrne A . the state of the world 's newborns. Washington: Save the children fund .2001.

7. UNICEF. The State of World's Children. 2017; 154-155.

8. Robert LS, Bishara JF, George HM, Jr. Bacterial and Fungal Infections. In: Mhairi GM, Martha DM, Mary MKS, editors. Avery's Neonatology-Pathophysiology \& Mangement of the Newborn. $6^{\text {th }}$ ed. Lippincott Williams \& Wilkinis, Philadelphia: A Wolters kluwei Company. 2005;1235- 1236 .

9. Lim NL, Wong YH, Boo NY, Kasim MS, Chor CY. Bactreaemic infections in a neonatal intensive care unit: A nine months survey. Med J Malaysia. 1995; 50: 59-63.

10. Airede AL. Neonatal septicemia in an African city of high altitude .J TropPediatr.1992; 38: 189-191.

11. Moreno MT, Vargas S, Poveda R, Sa'ez-Lloren X .Neonatal sepsis and Meningitis in developing Latin American. Paediatr Infect Dis J $.1994 ; 13: 516-520$.

12. Robillard PY, Nabeth P, Hulsey TC, Sergent MP ,Pe'rianin J ,Janky E .Neonatal nacterial septisaemiain a tropical area. Four year experiences in Guadeloupe (French West Indies). Acta Paediatr .1993; 82:687-689.

13. Hyde TB, Hilger TM ,Reingold A, Farley MM, O’Brien KL ,Schuchat A. Active Bacterial Core surveillance (ABCs) of the Emerging Infections Program Network. Trends in incidence and antimicrobial resistance of early onset sepsis: population based surveillance in San Francisco and Atlanta Pediatrics.2002; 110:690-695.

14. Health PT, Nik Yusoff NK, Backer CJ. Neonatal meningitis .Arch Dis Child Fetal Neonatal Ed.2003; 88:173-178.

15. Vesikari T, Janas M, Gro"nroos P, Tuppurainen N ,Renlund M ,Kero P ,Koivisto M, Kunnas M, Heinonen K ,Nyman R. Neonatal septicemia. Arch Dis Child.1985; 60:5422-5426.

16. Stoll BJ, Holman RC, Schuchat A: Decline in sepsis-associated neonatal and infant deaths in the United States, 1979 through 1994. Pediatrics. 1998;102: 1-7.

17. Stoll BJ, Gordon T, Korones S: Early-onset sepsis in very low birth weight neonates: A report from the National Institute of Child Health and Human Development Neonatal Research Network. J Pediatr. 1996;129: 72-80.

18. Chacko B, Sohi I: Early onset neonatal sepsis. Indian J Pediatr. 2005; 72: 23-26.

19. Daoud AS, Abuekteish F, Obeidat A, Al-Nassir Z, Al-Rimawi H: The changing face of neonatal septicaemia. Ann Trop Paediatr. 1995;15: 93-96.

20. Cordero L, Sananes M, Ayers LW: Bloodstream infections in a neonatal intensive-care unit: 12 years' experience with an antibiotic control program. Infect Control Hosp Epidemiol. 1999;20: 242-246.

21. Ganatra HA, Stoll BJ, Zaidi AK: International perspective on early-onset neonatal sepsis. Clin Perinatol. 2010; 37: 501-523. 
22. Baltimore RS, Huie SM, Meek JI, Schuchat A, O'Brein KL: Early-onset neonatal sepsis in the era of group B Streptococcal prevention. Pediatrics. 2001; 108: 1094-1098.

23. Kuruvilla KA, Pillai S, Jesudason M, Jana AK: Bacterial profile of sepsis in a neonatal unit in south India. Indian Pediatr. 1998;35: 851-858.

24. Aurangzeb B, Hameed A: Neonatal sepsis in hospital-born babies: Bacterial isolates and antibiotic susceptibility patterns. J Coll Physicians Surg Pak. 2003;13: 629-632.

25. Ahmed NU, Chowdhury MA, Hoque M, Darmstadt GL: Clinical and bacteriological profile of neonatal septicemia in a tertiary level pediatric hospital in Bangladesh. Indian Pediatr. 2002;39: 1034-1039.

26. Anwer SK, Mustafa S, ,Pariyani s ,Asraf S ,Taufiq KM.Neonatal sepsis : An etiologic study. J Pak Med Assoc.2000;50:91-94.

27. Joshi SG, Ghole VS, Nipadkar KB .Neonatal gram negative Bacteremia. Indian J Pediatr. 2000; 67:27-32.

28. Bhutta ZA. Neonatal Bacterial Infections in developing countries: Strategies for prevention. Semin Neonatol. 1999; 4:159-1571.

29. Motara F, Ballot DE, Perovic O .Epidemiology of neonatal sepsis at Johannesburg Hospital. Southern Afr J Epidimiol Infect.2005; 2220:90-93.

30. Kleon JO. From harmless commensal to invasive pathogen Coagulase -negative staphylococci. N Engl J Med 1990; 323:339-340.

31. Gladstone IM, Ehrenkranz RA, Edberg SC, Baltimore RS. A ten year review of neonatal sepsis and comparison with the previous fifty year experience .PediatrInfect Dis J. 1990; 9: 819-825.

32. Jahan N, Haque ZSM, Mannan MA, Akhter M, Yasmin S, Akter S, Talukdar AM, Dey SK. Patient characteristics, Bacteriological profile \& outcome of Neonatal Sepsis: A Hospital Based Study. CBMJ 2013 ; 02(01): 49-54. 34.

33. Rahman S, Hameed A, Roghani MT ,Rahman S ,Ullah Z . Multidrug resistant neonatal sepsis in peshwar, Pakistan. Arch Dis Child Fetal Neonatal. 2002;87:52-54.

34. Mugalu J, Nakakeeto MK, Kiguli S ,Kaddu- Mulindwa DH .Aetiology ,Risk factors and immediate outcome of bacteriologically confirmed neonatal septicemia in Mulago Hospital. Uganda . African Health Science. 2006; 6:120-126.

35. Umran K, Twun-Danso K. A case control study of neonatal sepsis: Experience from Saudi Arabia .J Trop Pediatr.1997; 43:84-88, 37.

36. Ramesh Bhat, Leslie ES L ,Vandana KE . Bacterial isolates of early onset neonatal sepsis and their antibiotic susceptibility pattern between 1988 and 2004: An audit from a center in India .Italian Journal of Pediatrics .2011; 37:32.

37. Rana U, Purani C, Petal P, Gupta K. Clinico-Bacteriological Profile of Neonatal Sepsis in a Tertiary Care Hospital. ARC Journal of Pediatrics.2016; 2(2):1-8.

38. Haque ZSM, Jahan N, Mannan MA, Hassan M, Begum M, Rob S, Akter M, Yasmin S, Hasnat SK. Identificaltion of Bacterial Isolates in Neonatal Sepsis and Their Antibiotic Susceptibility. MM J. 2014; 23(4):709-714.

39. Tallur SS, Kasturi AV, Nadgir SD , Krishna BVS. Clinico-bacteriological study of neonatal septicemia in Hubli. Indian J Pediatr.2000; 67:169-174.

40. Bizzaro MJ, Raskind C, Baltimore RS ,Gallagher PG .Seventy five years of neonatal sepsis at Yale : 1928-2003. Pediatrics. 2005; 116:595-602. 